\title{
THE EFFECT OF RECIPROCAL ARM ON THE SUPPORTING STRUCTURES OF THE ABUTMENTS IN CASES RETAINED BY UNILATERAL ATTACHMENT
}

\author{
Hesham I. AlmEldeen*
}

\begin{abstract}
Ten patients with kennedy class I classification utilizing OT unilateral extracoronal attachment were randomly divided in two groups using split mouth research design. Group I (without bracing arm) and group II (with a bracing arm on a prepared ledge at the survey line of the abutments). Radiographic evaluation of the abutments was made at time of denture insertion, 6months, 12 months, 18 months, and 30 months after denture insertion to measure the bone height changes around the abutments. The results obtained showed a statistically significant difference in bone loss around the abutment teeth between the two groups. In Conclusion patients rehabilitated with OT unilateral extracoronal attachment with a bracing arm showed less vertical bone loss around the abutments
\end{abstract}

KEYWARDS: Splinted abutments, bracing arm, unilateral distal extension, attachments.

\section{INTRODUCTION}

Removable partial dentures fabricated with precision attachments can be the viable options for patients in whom fixed prosthesis or dental implants are contraindicated. Precision attachment partial dentures can be a viable option in the treatment planning rather than long span fixed restorations. ${ }^{(1,2)}$

The attachments are formed of a patrix and a matrix portions. The semi-precision attachments are cast from castable patterns, while the precision attachments are prefabricated pre-machined with metal alloy that snugly fit to each other ${ }^{(3)}$.
Removable partial dentures retained with attachments are used to improve esthetics and biomechanics. They directed torque to the cervical portion of the abutment to improve the force distribution of the appliance. The force applied to the tooth is more apical than for occlusal or incisal rests, thus shortening the lever arm and decreasing torqueing forces. ${ }^{(4)}$

Skillfully designed conventional RPDs are not worn simply because the patients are usually dissatisfied with their appearance. Precision attachment has exceptional feature of being a

* Lecturer, Prosthodontics Dept. Faculty of Oral and Dental Medicine Future University, Cairo, Egypt. 
removable prosthesis with improved aesthetics, as elimination of the buccal or labial direct retainer or clasp arm is a key factor in establishing an esthetically acceptable design. Also less postoperative adjustments and better patient comfort are indication for the attachment RPD. ${ }^{(1,3)}$

Attachments are mostly indicated in long edentulous spans, distal extension bases and nonparallel abutments. Many recent studies greatly recommended that when abutments were of adequate clinical crown height to receive attachment; multiple abutments were splinted anterior to the edentulous span to aid in better distribution of stresses..$^{(1,5)}$

Extensive dental crown preparation, financial burden, complex clinical and laboratory procedures and difficulty in performing repairs are negative aspects of removable dentures associated with attachments. ${ }^{(7)}$

This study was carried out to evaluate the affect of using a reciprocal arm in unilateral attachment retained skeleton partial denture in distal extension cases.

\section{MATERIALS AND METHODS}

Ten patients were selected from the outpatient clinic, Prosthodontic department, Faculty of dentistry, Future University. The selected patients had the following criteria. All patients had Kennedy class I lower partially edentulous ridges with the first or second premolars were the last standing abutments. The remaining teeth had good periodontal condition, with no signs of attrition or gingival recession. Patients age ranged from 55-65 years. Patients with abnormal habits as bruxism or clenching were not included in the study. Preliminary impressions were made for the upper and lower arches using irreversible hydrocolloid impression material in properly selected and adjusted aluminum stock trays. The impressions were poured in dental stone to produce study casts. Study casts were mounted on a semiadjustable articulator (Easi Co, Ltd, Tokyo, Japan ) A face bow (Easi Co, Ltd, Tokyo, Japan) record was used to mount the upper cast. A provisional interocclusal wax record was made to mount the lower cast. Preoperative panoramic radiograph was made to detect the presence of impacted teeth, remaining roots or any pathological conditions.

Visual color determination of the abutment teeth using a shade guide was made before preparation. Two adjacent abutments on each side of the arch were prepared to receive two splinted ceramometallic crowns (Fig. 1). The finishing line was placed just below the free gingival margin. Gingival retraction was carried out using retraction cord introduced into the gingival crevice and left for five minutes before making the impression.

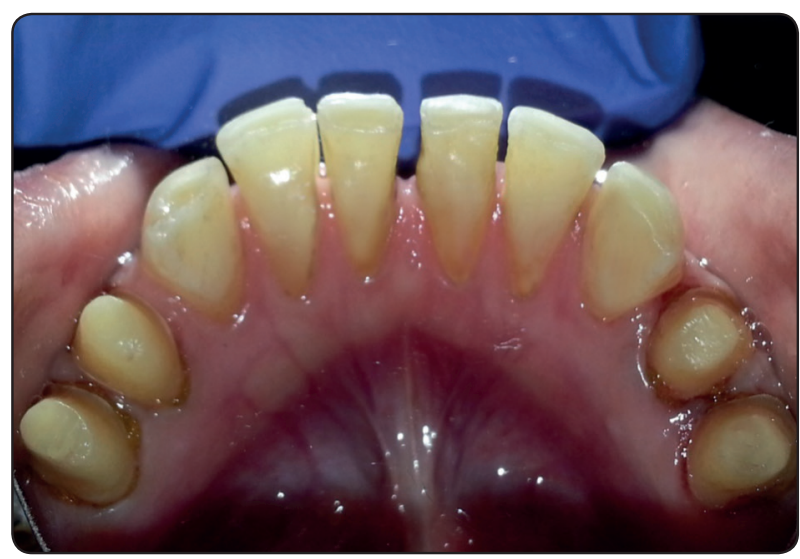

Fig (1) Intra-oral view, Kennedy class I lower partially edentulous ridge with prepared last two abutments.

An impression was made using silicone rubber impression material, and the prepared abutments were then protected with temporary crowns. The impression was poured in type IV improved stone and removable dies of the abutment teeth were obtained by sawing and then, wax patterns for the abutments were constructed. Unilateral OT attachment (Rhein 83 OT unilateral) was used in split mouth research design.Group I received (OT unilateral extracoronal attachment and wax pattern for the abutment were made without ledge, since the 
abutments will not receive a bracing arm) and group II received a modified OT unilateral extracoronal attachment with a bracing arm and wax pattern for the abutment were made with a ledge to receive a bracing arm from the removable partial denture. In a split-mouth design.

Then OT Unilateral attachment Kit were used (Fig 2), The male portions of the plastic pattern of the attachments were joined to the distal surface of the wax pattern of the last abutments $1 \mathrm{~mm}$ away from the gingival margin. This was carried out with the aid of surveyor (fig 2).

Spruing, investing, burn out and casting were carried out according to the manufacture's instruction. The casting was sandblasted, finished and polished except the male portion of the attachment. The finished castings were tried in the patient's mouth and checked for seating, retention and proper adaptation of the finishing line. Porcelain was then fired to the metallic crowns. Try in of the crowns were carried to check proper occlusion and contact with the adjacent teeth. (fig 3).

Centric occluding relation were recorded. Setting up of cross linked acrylic resin teeth and then try- in were done.

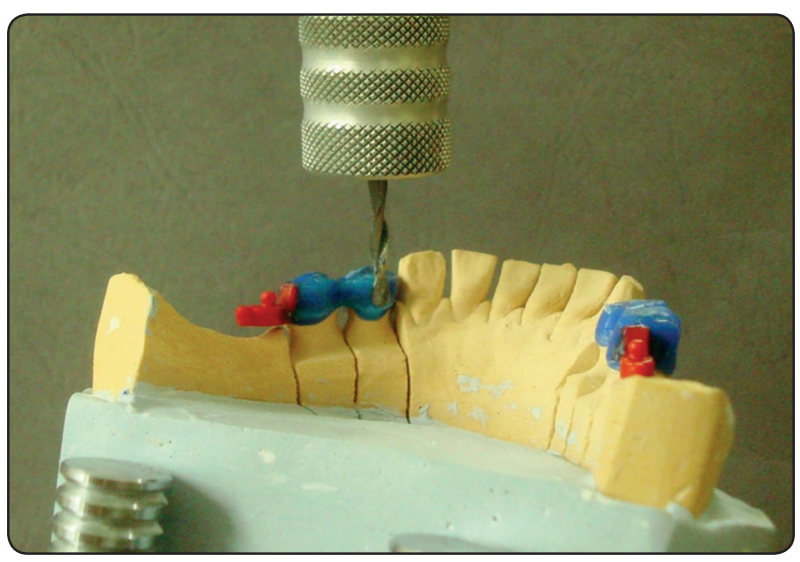

Fig.(2) Ledge preparation on the second premolar for receiving the bracing arm only at one side.
Denture processing was carried out. After deflasking, laboratory remounting was carried out to correct processing occlusal errors and dentures were then finished and polished.

The porcelain crowns were finally cemented to the abutment teeth and the denture was inserted and used to fix the crowns accurately during cementation.

In the recall visits, patients were evaluated radiographically to measure the bone height changes around the natural abutments at time of denture insertion, 6months, 12months, 18 monthss and 30 months.

The Digora computerized system (Digora computerized system, Helsinki, Finland), the Rinn XCP periapical film holder (Rinn manufactures Co. Ligin, III, USA) and a specially constructed acrylic template were used for taking standardized and reproducible serial digital images for the natural abutments using the long cone paralleling technique.The digital images were analyzed to evaluate the marginal bone level distal to the last abutment at three different points with the same fixed landmarks. ${ }^{(8)}$

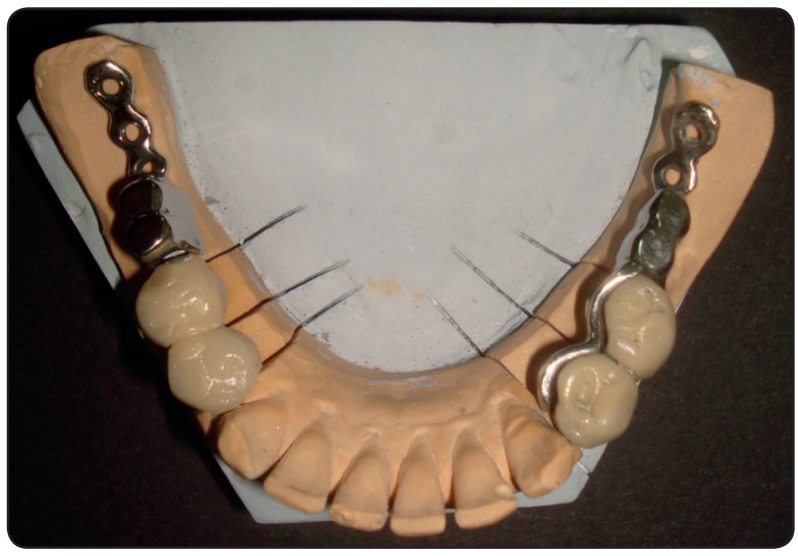

Fig. (3) Porcelain crown with the attachment also showing the prepared ledge on the right side of the cast for receiving the bracing arm. 
The first a line (first line) was drawn horizontally and tangential to the apex of the root of the last abutment. The second and third vertical lines were drawn at equal distances from each other from the highest level of the alveolar crest to the horizontal line the first line and perpendicular on it. Fig. (4)

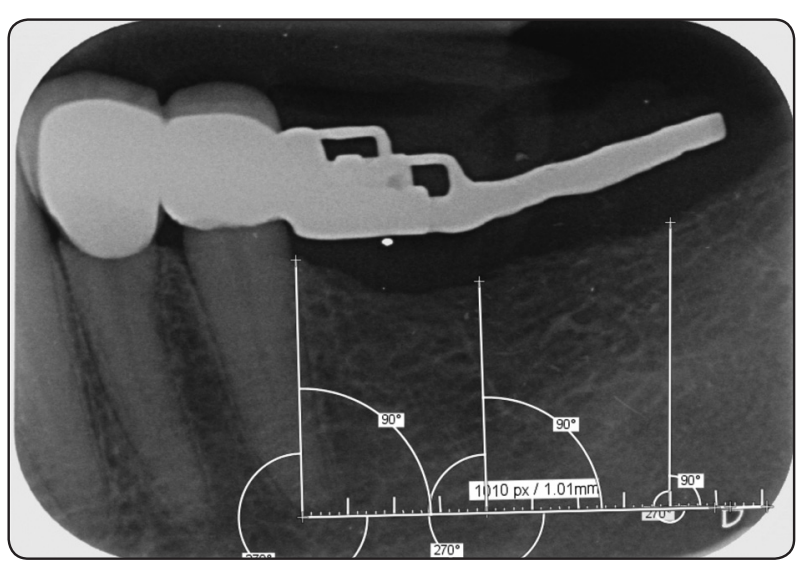

Fig (4) Measuring the marginal bone level distal to the last abutment at three different points with the same fixed landmarks.
The marginal bone height along each of the three lines was measured and the mean values of the three readings distal to the last abutment were recorded, tabulated and statistically analyzed.

\section{RESULTS}

This study was classified as split-mouth study and was performed to evaluate bone height changes around unilateral attachments during thirty months follow up period.

For both groups individually, one way analysis of variance (ANOVA) test was performed followed by Tukey`s post hoc test for multiple comparisons during thirty months follow up. A statistically insignificant difference was observed along the follow up periods as( P-value $>0.05)$, ( table (1), figure (5)).

For comparison between both groups for each follow up period, paired t test was performed which revealed a statistically significant difference between both groups along follow up periods as (P-value < 0.05). ( table (1) figure (5)).

TABLE (1) Comparison between bracing and non-bracingside during thirty months follow up period:

\begin{tabular}{|c|c|c|c|c|c|}
\hline \multirow{2}{*}{ Bone Height Change } & \multicolumn{2}{|c|}{ Bracing Side } & \multicolumn{2}{|c|}{ Non Bracing Side } & \multirow{2}{*}{ P-value } \\
\hline & Mean & SD & Mean & SD & \\
\hline Baseline- Three months & $0.59^{\mathrm{a}}$ & 0.11 & $0.91^{\mathrm{a}}$ & 0.11 & $<0.0001 * *$ \\
\hline Baseline- Six months & $0.62^{\mathrm{a}}$ & 0.11 & $1.01^{\mathrm{a}}$ & 0.14 & $<0.0001 * *$ \\
\hline Baseline- Nine months & $0.65^{\mathrm{a}}$ & 0.12 & $1.04^{\mathrm{a}}$ & 0.17 & $<0.0001 * *$ \\
\hline Baseline- Twelve months & $0.72^{\mathrm{a}}$ & 0.13 & $1.05^{\mathrm{a}}$ & 0.18 & $<0.0001 * *$ \\
\hline Baseline- Eighteen months & $0.77^{\mathrm{a}}$ & 0.14 & $1.07^{\mathrm{a}}$ & 0.25 & $<0.0001 * *$ \\
\hline Baseline- Thirty months & $0.81^{\mathrm{a}}$ & 0.15 & $1.09^{\mathrm{a}}$ & 0.27 & $<0.0001 * *$ \\
\hline P-value & $0.06^{*}$ & & & & \\
\hline
\end{tabular}

M; Mean, SD; Standard deviation, P; Probability Level

Values with same superscript letter in the same column were insignificant different 


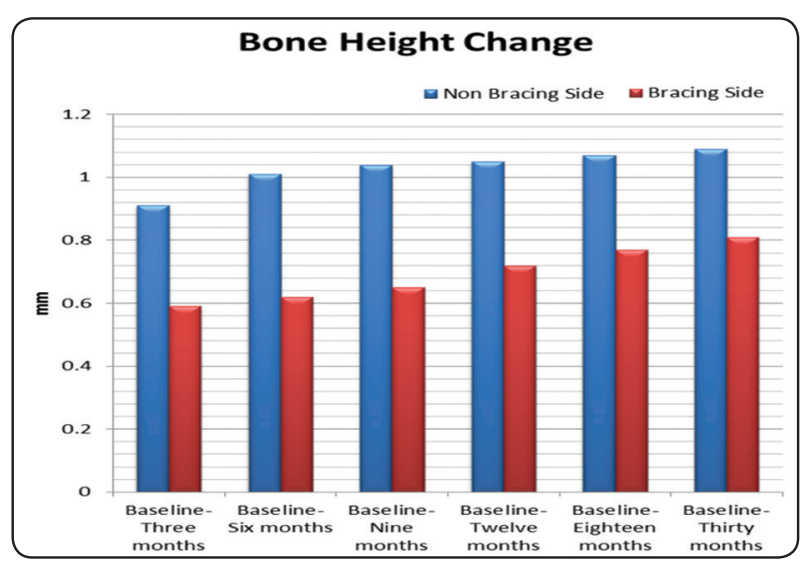

Fig. (5) Comparison between bracing and non-bracing side during thirty months follow up period

\section{DISCUSSION}

This study was carried out on ten male partially edentulous patients with age ranged from 40-55years. As the female patient may have hormonal disturbance which may effect alveolar crest height and alveolar bone density changes. ${ }^{(\mathbf{9}, 10)}$

The selected patients were free from any systemic diseases that may affect the results of the study. ${ }^{(11,12)}$

Inter-occlusal and buccolingual space are critical clinical factors when selecting the desired ball attachment and retentive matrix. Problems can occur when an inter-occlusal space deficiency is not recognized. ${ }^{(13)}$

Two splinted crowns were used on either side for better distribution of forces, good support and improving the prognosis of partial denture. ${ }^{(14,15)}$

The split- mouth research design in the present study guard against variables as bone quality and quantity, occlusal loads, preferable side chewing, soft tissue and oral hygiene measures are applicable to both sides of the mouth. ${ }^{(16,17)}$

To avoid the quick loss of the performances of the OT unilateral partial denture, replacement of the retentive caps once a year is suggested by the manufacture to avoid loss of retention which allows the lateral movement of the prosthesis and exerts extra forces on the abutments. ${ }^{(18)}$
With the introduction of unilateral attachment, it was possible to restore distal extension areas without the need of cross arch extension Sravanthi ${ }^{(1)}$ mentioned that the support of RPD and its connection with fixed prosthesis generates cross arch stability throughout masticatory activity and permits function similar to that of fixed prosthesis. Use of attachment system minimizes stresses and eliminate metal display which improves esthetics.

Computerized image Plate and Film Holder System Set Color instrument sets together with a long cone Paralleling Technique in x-ray diagnosis. As well as individually constructed radiographic template provided standardized reproducible images without any geometric variation, as it allowed for a fixed target to film distance. Moreover, the sixteen inch long cone directed only parallel rays to the image plate, thereby preventing the magnification of the image. ${ }^{(19,20)}$

When fixed partial dentures were not considered due to long edentulous span and when implants were also not considered as the patient was not ready for the surgical procedure. Therefore, attachments and cast partial denture were selected as the treatment of choice in order to achieve functional requirements in long term edentulous spans and distal extension bases. ${ }^{(1,21)}$

Increased stability and retention with a predictable occlusion are the advantages of this system. As the system is relatively rigid, there is minimal movement in the prosthesis. There is no need to extend the appliance across the arch, thus reducing the bulk of material in the mouth and, therefore, less soft and hard tissue coverage. The patient has better speech and more confidence and comfort while eating Because of improved stability and retention. ${ }^{(\mathbf{2 1})}$

The semi-precision system leads to high patient satisfaction, better quality of life for the patient, in that there is enough retention so the RPD is not easily dislodged, yet is relatively easy to remove and replace for patient acceptance. (21) 
Radiographic evaluation showed that the bracing side causes less bone resorption than non-bracing side. This could be attributed to the effect of bracing arm in sharing some of loads transmitted to the supporting structures. This is in agreement with the previous studies which showed that the crown ledge or shoulder provides effective stabilization and reciprocation and also acts as an auxiliary indirect retainer. ${ }^{(22,23)}$

The numerical value of bone resorption at the non-bracing side, although this increase is not significant, could be attributed to the yielding of the prosthesis at the free end of the cantilever.

Recent studies recommended the use of many extra coronal attachments with stress releasing properties in unilateral distal extension cases such as Dalbo, Ceka, and ERA, , which produce equal stress distribution between the abutments and the residual alveolar ridges. ${ }^{(24)}$

This unilateral attachment provides lateral stability and distal support to the prosthesis. It provides also superior retention, controlled resiliency, overall functionality and economical solutions. ${ }^{(25)}$

It could be concluded the results of this study that both group 1(unilateral attachment retained distal extension partial dentures) and group 2 (modified unilateral attachment retained distal extension partial dentures with a bracing arm) could be a predictable modality in treatment of distal extension ridges.

\section{REFERENCES}

1. Sravanthi G, Dinesh B, Taruna M, Prasad V: Unilateral Attachment Retained Distal Extension Removable Partial Denture, Indian J Dent Adv 2014; 6(4): 1727-1730.

2. Feinberg E: Precision Attachment Case Restoration With Implant Abutments: A Review With Case Reports, Journal of Oral Implantology. 2011; 37(4):489-498.

3. Vaidya S, Kapoor C, Bakshi Y, BhallaS:Achieving an esthetic smile with fixed and removal prosthesis using extracoronalcastable precision attachments. The Journal of Indian Prosthodontic Society 2015;15(3):284-288.
4. Santos J, Cruz L, Alfenas B, Oliveira F, Filho J.: Maxillary Rehabilitation Using Fixed and Removable Partial Dentures with Attachments: A Clinical Report. Journal of Prosthodontics [serial online]. January 2014;23(1):58-63.

5. Nayar S, Bhuminathan S, Mahadevan R.: Combination restoration in full mouth rehabilitation. J Pharm BioallSci 2015;7:S288-90.

6. Jain AR, Philip JM and Ariga P:Attachment- retained unilateral DistalExtension (Kennedy's class II modification I) Cast partial Denture . Int J ProsthodntRestor Dent 2012; 2(3):101-107.

7. Reis SN, Maurício J, Cruz Perez LE, Alfenas BFM, Oliveira Abi-Rached F. Maxillary Rehabilitation Using Fixed and Removable Partial Dentures with Attachments: A Clinical Report. Journal of Prosthodontics. 2014; 23(1):58-63.

8. Schneider C, Rasband W, Eliceiri K.: NIH Image to Image J: 25 years of image analysis. Nat Meth.2012; 9(7):671-5.

9. Von Womern N and Kollerup G.: Symptomatic osteoporosis - a risk factor for residual ridge reduction of the jaw . J .Prosthet. Dent.1992; 67:656-660.

10. Curtis D.A, Curtis T.A ,Wagnild C.W and Finzen F.C: Incidence of various classes of removable partial denture. J. Prosthet. Dent. 1992; 67(5):664-667.

11. Kim J, Amar S. Periodontal disease and systemic conditions: a bidirectional relationship. Odontology / the Society of the Nippon Dental University. 2006; 94(1):10-21.

12. Lambert, P., Morris, H., Qchi, S: The influence of smoking on 3 years old clinical success of osseointegrated dental implants. Ann. Periodontal. (5): 1:79,2000.

13. Anantharaju A, Joseph B, Kusum C, Nooji D: Connectors and attachments in oral rehabilitation, Journal of Dr. NTR University of Health Sciences 2013;2(3): 222-226

14. Chou TM, Eick JD, Moore DJ, Tira DE. Stereophotogrammetric analysis of abutment tooth movement in distal-extension removable partial dentures with intracoronal attachments and clasps. The Journal of prosthetic dentistry. 1991;66(3):343-9.

15. Abd-El-Nabi, M. H.S.: Evaluation of stress breaker and splint in partial dentures with extracoronal precision attachments. Ph.D Thesis Cairo University, 1998.

16. HermansA, De bruyn H and. D'haese J : Split-mouth study of short/wide dental implants, used as alternative for bone augmentation, vs. long dental implants, Clin. Oral Impl. Res., 2014;437 
17. Rubel B and Hill E.: Unilateral Semi-Precision Removable Partial Denture Utilizing Bredent VKS-SG Attachment System. New York State Dental Journal [serial online], 2009;75(4):36-38.

18. Banerjee S, Bera A, Gupta T, Banerjee A. Attachment Retained Removable Prosthesis - A Case Report. Clinical Dentistry, 6(7):30-35, 2012.

19. Berry M, Chowdhury V and Suri S: Diagnostic Radiology: Advances in Imaging Technology. Jaypee Brothers Medical Publishers (P), New Delhi, 2000; 221-233.

20. Aktan AM, Çiftçi ME, Akgünlü F: Comparison of the Delay in Processing Time and Protective Plastic Cases in Two Phosphor Plate Systems. The Scientific World Journal. 2012;2012:850764.

21. Schuh C, Adiel S, Mesko M, Valentini F, Pereira-Cenci $\mathrm{T}$ andBoscato N. Resilient Attachments as an Alternative to Conventional Cast Clasp Removable Partial Denture:
3-Year Follow-up. The Journal of the Indian Prosthodontic Society. 2014; 14(Suppl 1):273-278.

22. El Sayed M: Stress analysis study of two treatment modalities rehabilitating distal extension cases with few remaining natural teeth. C.D.J. 2008; 24 (3) :379-393.

23. Ogata K: Longitudinal study on torque around sagital axis in lower distal extension dentures. J. Oral Rehab. 1993; 20: 203.

24. Wang H-y, Zhang Y-m, Yao D, Chen J-h. Effects of rigid and non-rigid extracoronal attachments on supporting tissues in extension base partial removable dental prostheses: a nonlinear finite element study. The Journal of prosthetic dentistry.; 105(5):338-46,2011.

25. Ghorab, SAM.: Comparative study between two different deigns for Kennedy class I with one anterior modification. Ph.D. Thesis, Cairo University, 2000. 